\title{
Janvier 2021
}

\section{Chaleur hellénique}

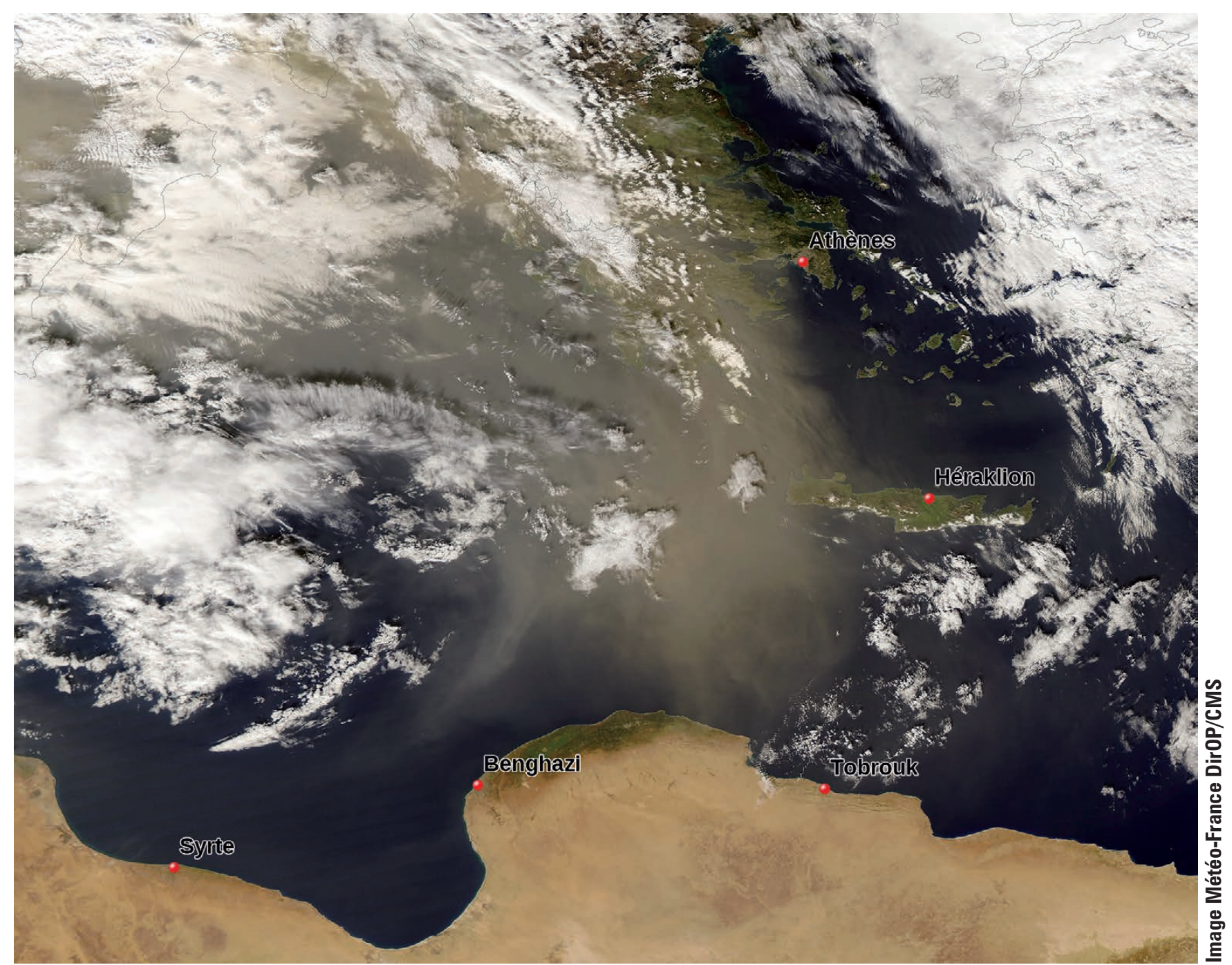

Aqua - Le 9 janvier 2021 à 11 h 30 TU - Image en vraies couleurs

'est le sirocco, vent chaud et sec en provenance d'Afrique, qui arrache les poussières de sable du Sahara

et les transporte au-dessus de la mer M éditerranée jusqu'en $\mathrm{G}$ rèce. Les épisodes de sirocco sont plus fréquents à l'automne et au printemps quand une dépression to urbillonne sur l'ouest de la M éditerranée. En ce mois de janvier, ce type de situation météorologique est pilotée par Filomena, la tempête qui provoque des chutes de neige exceptionnelles en Espagne. Pendant que les $M$ adrilènes font d'immenses bonshommes de neige, la température de plus de $22^{\circ} \mathrm{C}$ incite les habitants d'A thènes à rejoindre les plages, les parcs et les jardins. La température maximale atteint même $28,3^{\circ} \mathrm{C}$ dimanche 10 janvier à La Canée, ville de 55000 habitants à l'ouest de la Crète, I'une des températures de janvier les plus élevées en cinquante ans ! 


\section{Janvier 2021}

\section{Sur les traces de}

\section{Fillomena}

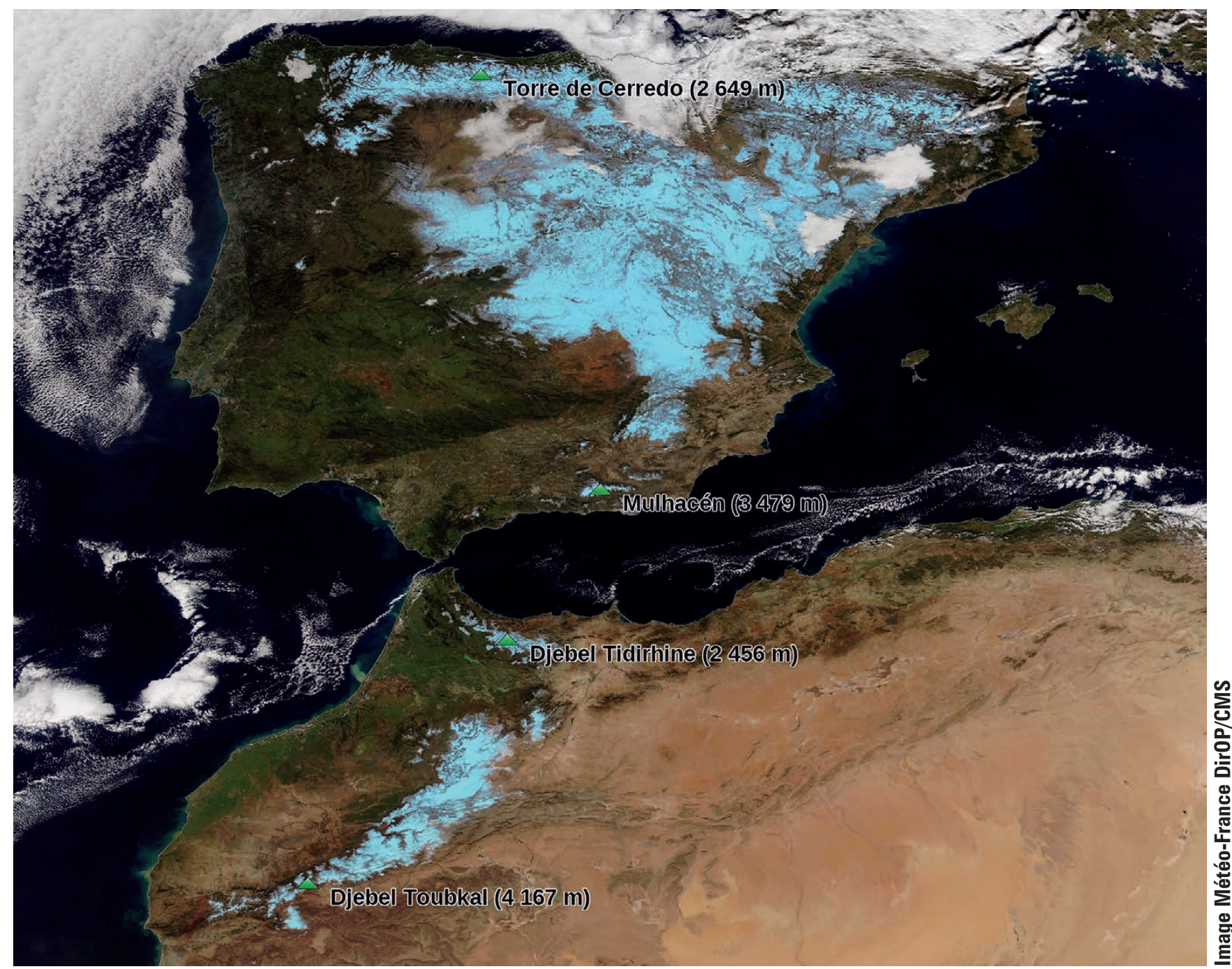

Noaa-20 - Le 13 janvier 2021 à 13 h 10 TU - Image en composition colorée neige

es Espagnols se souviendront longtemps du passage de la tempête Filomena! Vendredi 8 et samedi - 9 janvier, la neige est to mbée sur un large quart nordest de la péninsule ibérique, comme en témoigne cette image prise quelques jours plus tard. Les hauteurs de neige relevées à M adrid - plus de $40 \mathrm{~cm}$ - sont exceptionnelles. Cet épisode est suivi d'une vague de froid intense. Le service météorologique national espagnol indique avoir enregistré $-25,4{ }^{\circ} \mathrm{C}$ dans un village d'Aragon au nord-est de M adrid. Les perturbations successives de janvier ont aussi saupoudré de neige les sommets des chaînes montagneuses du M aroc: I'Atlas marocain, qui s'étend sur une longueur de $1000 \mathrm{~km}$ environ dans une direction sud-ouest/nord-est, et sur le Rif, région septentrionale du M aroc qui borde la mer M éditerranée. 